\title{
Creativity Encounters Between Children and Robots
}

\author{
Patrícia Alves-Oliveira \\ patricia_alves_oliveira@iscte-iul.pt \\ Lisbon, Portugal \\ Matthew A. Cronin
mcronin@gmu.edu
George Mason University
Fairfax, VA, US
}

Iscte-Instituto Universitário de Lisboa, CIS-IUL, INESC-ID

\author{
Patrícia Arriaga \\ patricia_arriaga@iscte-iul.pt \\ Iscte-Instituto Universitário de Lisboa, CIS-IUL \\ Lisbon, Portugal \\ Ana Paiva \\ ana.paiva@inesc-id.pt \\ Instituto Superior Técnico-UL, INESC-ID \\ Lisbon, Portugal
}

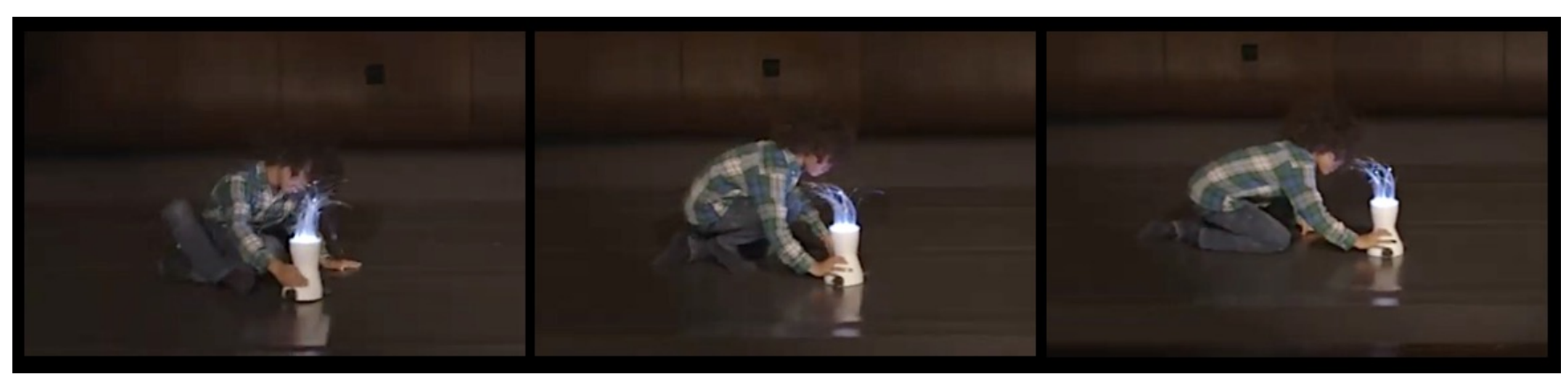

Figure 1: Play sequence between a child and the YOLO robot.

\begin{abstract}
Creativity is an intrinsic human ability with multiple benefits across the lifespan. Despite its importance, societies not always are well equipped with contexts for creativity stimulation; as a consequence, a major decline in creative abilities occurs at the age of 7 years old. We investigated the effectiveness of using a robotic system named YOLO as an intervention tool to stimulate creativity in children. During the intervention, children used YOLO as a character for their stories and through the interaction with the robot, creative abilities were stimulated. Our study $(n=62)$ included 3 experimental conditions: i) YOLO displayed behaviors based on creativity techniques; ii) YOLO displayed behaviors based on creativity techniques plus social behaviors; iii) YOLO was turned off, not displaying any behaviors. We measured children's creative abilities at pre- and post-testing and their creative process through behavior analysis. Results showed that the interaction with YOLO contributed to higher creativity levels in children, specifically contributing to the generation of more original ideas during story creation. This study shows the potential of using social robots as tools to empower intrinsic human abilities, such as the ability to be creative.
\end{abstract}

Permission to make digital or hard copies of all or part of this work for personal or classroom use is granted without fee provided that copies are not made or distributed for profit or commercial advantage and that copies bear this notice and the full citation on the first page. Copyrights for components of this work owned by others than ACM must be honored. Abstracting with credit is permitted. To copy otherwise, or republish, to post on servers or to redistribute to lists, requires prior specific permission and/or a fee. Request permissions from permissions@acm.org.

HRI '20, March 23-26, 2020, Cambridge, United Kingdom

(c) 2020 Association for Computing Machinery.

ACM ISBN 978-1-4503-6746-2/20/03 . \$15.00

https://doi.org/10.1145/3319502.3374817

\section{ACM Reference Format:}

Patrícia Alves-Oliveira, Patrícia Arriaga, Matthew A. Cronin, and Ana Paiva. 2020. Creativity Encounters Between Children and Robots. In Proceedings of the 2020 ACM/IEEE International Conference on Human-Robot Interaction (HRI '20), March 23-26, 2020, Cambridge, United Kingdom. ACM, New York, NY, USA, 10 pages. https://doi.org/10.1145/3319502.3374817

\section{INTRODUCTION}

Robinson (2001) characterized creativity as being at the heart of what it is to be human [1]. During childhood, we spend most of our time between fantasy and pretend play, creating new worlds and exploring [2]. As we grow older, critical thinking skills take over and gradually we let go of the creative elasticity that our brain was functioning for. So despite becoming more efficient and skilled, we also become less risk-taking, exploratory, and original [3, 4]. We, therefore, might trait our fearless creative imagination for a more grounded and functional sense of the world.

The benefits of being creative are numerous. Creativity is a skill related to well-being and healthy development and relates to our sense of self-expression and identity $[5,6]$. It can be what contributes to moods of joy, wonder, excitement, efficiency, and pleasure $[7,8]$. Additionally, creativity is considered a transferable skill since it benefits several areas of human development, growth, and learning $[9,10]$. Creativity levels are dynamic and are likely to change during life [11]. Therefore, despite its benefits, the first major oscillation in creative abilities occurs at the age of 7 years old [12-14] At this age, an intense tendency for creativity levels to decrease is reported to occur in a phenomenon named "creativity crisis" [15]. This decline has been associated with diverse factors, such as to the organization of traditional education systems and 
conformity behaviors towards peers that children start to exhibited in this developmental stage [16, 17].

Creativity is a skill that can be developed if trained [18]. However, existing creativity training programs for children are still rare to find and existing ones resemble test-like formats, lacking elements of joy and play, essential to children [17, 19]. Given the willingness and benefits of children interacting with technology [20], we aim to test the impact of a social robot on children's creativity levels (see Figure 2 for an overview of an interaction). In our intervention scenario, children used a robot as a character for their stories, similar to how they manipulate traditional toys, such as dolls or cars, for storytelling and fantasy creations. We aimed at studying the effectiveness of children using a robot in stimulating their creativity in comparison with the same robot that was turned off, i.e., the robot did not display any interactive behaviors. We then measured the impact of the intervention across two creative dimensions. The first dimension concerned the creative person, in which creative abilities were evaluated using pre and posttests of verbal [21] and figural-graphic creativity [22]. The second dimension concerned the creative process in which the creativity present in the process of story creation was measured by analyzing the fluency, flexibility, elaboration, and originality of ideas generated by children [23].

\subsection{Contributions}

There are two main contributions of this work. The first contribution relates to the application of a social robot in a creativitynurturing environment under activities that children are familiar with, namely unstructured play and storytelling. Leveraging on activities that children practice and that are part of their everyday life is a contribution as most interventions with robots are tailored to the capabilities/limitations of the robot itself instead of potentiating the way children interact. Our research incorporates a robot into a storytelling context with no turn-taking restrictions thus attending to play dynamics observed in children. Also, by using storytelling as the main intervention activity we do not place an extra cognitive load on children and they can be focused on content creation. Additionally, while most child-robot interactions are restricted to specific physical spaces due to power outlet dependency of the robot or due to its heavy hardware, the robot used within this research can be carried around by children, favoring unrestricted play dynamics. These were the main design drives for this work which are aligned with the Product Design Framework that states that a successful product is developed taking into account existing dynamics between users and their environment [24, 25].

The second contribution of this work concerns the thorough evaluation of creativity. The majority of creativity evaluations consist of using questionnaires to measure differences in creative abilities before and after the intervention (usually named as pre- and posttests). In our study, we go beyond this and analyzed the creative process of children while creating a story with the robot. The creative process is usually deemed chaotic and most of the time messy and contains ideas that might not be visible or identifiable in a final outcome and end up going unnoticed (see Figure 4). In our study, we not only analyzed the impact of the intervention at preand post-testing levels, as we also analyzed the creative process of children. The creative process was studied by using an objective

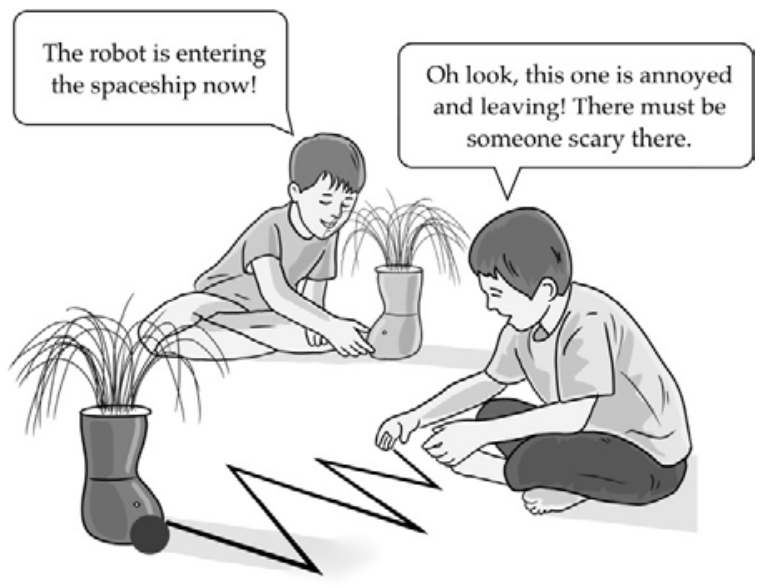

Figure 2: Example of interaction between children and robots for creativity stimulation during storytelling play. Children move the robots about the floor as a storytelling character stand-in. Based on the trajectories detected by the robots' motion sensors, they take on different personalities that either mirror or contrast the children's storyline, as a creativity-stimulating technology intervention.

scoring system for creativity that measures the fluency, flexibility, elaboration, and originality of the ideas generated [23, 26, 27]. This analysis has the potential to shed light and a deeper understanding of the cognitive processes that children undergo while interacting with a robot whose goal is to provoke creativity.

\section{RELATED WORK}

In this section, we review previous work regarding how creativity has been defined and measured. Additionally, we contemplate how robots have been used in the context of creativity.

\subsection{Defining creativity}

Creativity is considered one of the highest human cognitive abilities [28]. It is a multi-faced concept with over 60 different definitions in the field of psychology alone [29, 30]. While earliest definitions of creativity described this ability as a function of an individual [23], creativity definition has evolved and is now defined as an interaction between aptitude, environment, and process by which an individual or a group produces a tangible product that is both novel and useful, within the social context [31]. Guilford (1967) defined creativity as the embodiment of thought in the form of external behavior, consisting of three characteristics: fluency, flexibility, and originality [23]. Amabile (1996) regarded creativity as the interaction between the individual and its external environment, including three components: domain-relevant skills, creative-thinking skills, and task motivation [32].

Sawyer (2017) understood creativity in the context of a group emergence where flow, collaboration, and improvisation processes take place. He stated that when group synchronization is reached, it becomes difficult to discriminate the individual contribution of each person, as "the whole is greater than the individual parts" 
[33]. Indeed, group dynamics influence creativity due to the unpredictability of the other's creations and one's need to adapt and keep up with a coherent narrative [34]. The characteristics of every person in the group also bring richness to the creative context that in individual creations is not possible to attain [35, 36]. Thus, despite finding on individual creativity being more extensively reported in the literature, group creativity seems to bring a new layer to creations. Additionally, Cronin and Loewenstein (2018) argued that creativity is a process of following cues to generate insights that change our perspectives, which with the craft we can use to form inventions and enlightenment [37]. In this work, we rely on definitions provided by different authors and view creativity as a process of discovery, connections, and insights that are influenced by variables related to the creative person and the creative process.

\subsection{Measuring creativity}

Creativity can be measured according to three main dimensions: creative person, creative process, and creative product [38].

When focusing on the creative person, creativity is evaluated using psychometric validated tests of creativity that can fall into two different creativity domains: the verbal creativity and the graphicfigural domains. The verbal creativity domain is represented by high levels of creativity related to verbal/written expression [21], present in e.g., poets. While the figural-graphic domain [22], evaluate creativity in visuals, such as drawings, being a type of creativity more evident in artists such as painters or sculptors.

The creative process is related to ideas generated while trying to solve a problem, create a solution, or during brainstorming sessions. Usually, these ideas are the most creative as the limits and boundaries around their expression are lowered for the sake of creative emergence; however, data related with creative processes are also harder to analyze as they are messy (several ideas can emerge at the same time with no obvious link between them), time-consuming (usually requires analyzing the behavior or verbal content of creative sessions) and difficult to discuss (not many reported methods for identifying and bench-marking content of creative processes). One suggested way to analyze the creative process, although rarely presented in research findings, is to use a coding system for creativity that measures the fluency, flexibility, elaboration, and originality of the ideas generated [23, 26, 27].

The creative product, or the outcome of a creative process, is generally analyzed using the Consensual Assessment Technique (CAT) [39], which relies on a panel of experts in the field related to the product generated to act as judges and measure how creative a certain product is. Given the difficulty of having experts as judges, a new technique emerged, called the Creative Solution Diagnosis Scale (CSDS) [40]. This new method adheres to a similar evaluation principle to the one used in CAT but differs from it in that a panel of non-experts carries out the evaluation of the product. Generally, CSDS requires a larger sample of judges than the CAT technique.

\subsection{Robots for creativity}

Given the importance of creativity, literature reports on some efforts of using social robots for creativity stimulation. A study conducted by Khan et al. (2016) used a social robot to encourage adult participants in generating creative ideas for a Zen Rock Garden. The

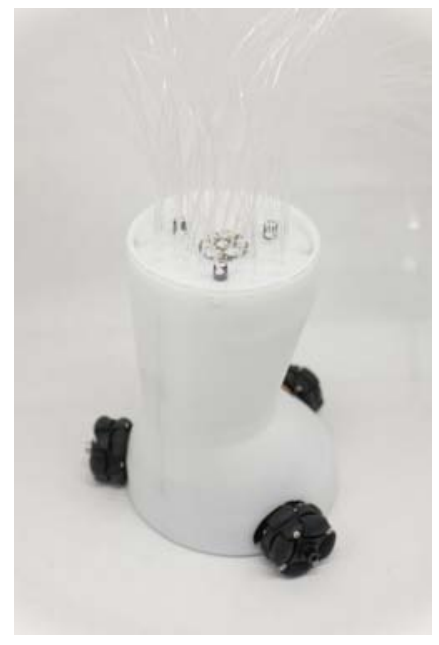

Figure 3: YOLO, the robotic platform used in this work.

results of this study showed that participants engaged in the creativity task for longer periods of time and provided almost twice the number of creative expressions when a robot encouraged them to generate creative ideas compared to an encouraging PowerPoint slideshow [41]. A study carried out by Ali et al. (2019) emulated creativity in a robot and studied if children's creativity levels increased after interacting with this robot compared to a robot that did not exhibit creativity behaviors. The authors found that children who interacted with a creative robot generated more ideas, explored more themes, and were more original, than children who interacted with a non-creative robot [42].

Additionally, creative performance can be a factor of different mindsets, i.e., one's implicit theory about weather creative abilities are unchangeable/fixed or can be nurtured/grow [43]. This line of research showed that a growth mindset is associated with variables related to creative thought, such as problem-solving [44, 45]. A study conducted by Park et al. (2017) developed a social robot with a growth mindset and another robot with a neutral mindset and compared if children's mindsets can be influenced by the interactions with these two different robots. The authors concluded that children that were exposed to a robot with a growth mindset were more motivated to solve a difficult task and self-reported having a stronger growth mindset in comparison with the neutral version [46]. A different study focused on curiosity, a trait deeply related to creativity [47]. Therefore, Gordon et al. (2015) designed a social robot that expressed curiosity behaviors, and the main goal of this study was to analyze the effects of this robot on children's own curiosity levels. Results showed that children's curiosity levels were higher after interacting with the curious compared to a robot that did not exhibit curiosity behaviors [48]. An additional study confirmed similar effects of curiosity contagion between robots and the adult population [49].

\section{ROBOTIC SYSTEM}

We used YOLO, a short name for Your Own Living Robot, a social robot designed and developed to stimulate creativity in children 


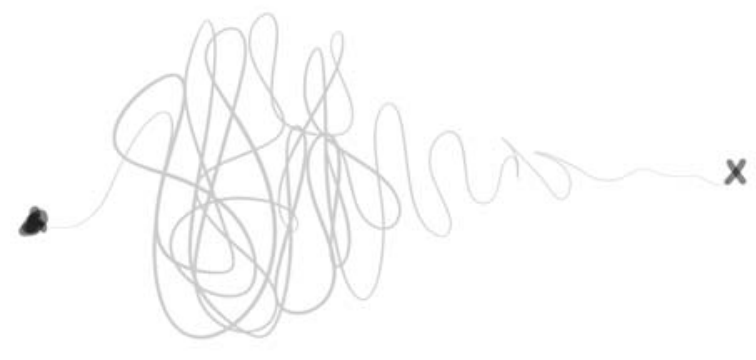

Figure 4: Creative process. The dot represents the starting point of the creative process, the entangled lines in the middle part demonstrate a rich generation of ideas that become organized when the creative process finishes (illustrated with a cross). In our work, we evaluated the creative process of storytelling by measuring the fluency, flexibility, elaboration, and originality of ideas.

(see Figure 3). This is a small-size and light-weight robot with an abstract shape [50]. YOLO interacts with children using lights with different colors and distinct movements at various speeds. These implicit interaction modes and the shape of the robot set realistic expectations for the robot capabilities [51] (see Figure 1).

To stimulate creativity in children, the robot was designed following grounded theories on creativity in which two creativity nurturing techniques were embedded in its behavior expression. These techniques are called "Mirroring" and "Contrasting”. When YOLO using the Mirroring technique it replicates the same movement that children performed, thus it was implemented to stimulate convergent thinking, i.e., as an elaboration process since it follows the same pattern initiated by children (e.g., the robot continues the same movement of the child, thus elaborating on that idea) [52] When using the Contrasting technique, YOLO exhibits different movements from the one created, therefore this movement was implemented to stimulate divergent thinking as a different course for the story is hinted (e.g., the robot runs in a different direction than the one defined by the child, which may promote opportunities for a plot twist) [53].

YOLO decides on which technique to apply according to the storytelling arc of the story. Convergent thinking was implemented during the initial and final stages of the story where children are setting up or finishing the plot. Divergent thinking was implemented during the middle part of the story where original ideas emerge. Each storytelling stage was defined by time instances for each storytelling stage. The software [54] and the hardware [50] of YOLO were released in open access and additional details about the robotic system can be found in the associated publications.

\section{METHOD}

We present details on the method used in this experimental study.

\subsection{Goal, conditions, and hypothesis}

We tested the impact of a social robot on children's creativity levels During the intervention, we expect YOLO to stimulate divergent and convergent thinking, two important forms of creative thought that call for two different cognitive states [23]. We compared the efficacy of YOLO in stimulating children's creativity across 3 study conditions: i) simple condition, in which YOLO displayed behaviors based on creativity techniques; ii) enhanced condition, in which YOLO displayed behaviors based on creativity techniques plus social behaviors; iii) control condition, in which YOLO was turned off. The hypothesis for our study are the following:

Hypotheses 1: Creative person - The impact of the intervention in verbal and graphic-figural creativity will be higher when interacting with a robot loaded with creativity stimulating behaviors (simple condition) or with a robot with creative and social behaviors (enhanced condition) in comparison with the same robot that does not display any behaviors (control condition).

Hypotheses 2: Creative process - Children's creative process of storytelling contains more creative ideas when interacting with a robot loaded with creativity stimulating behaviors (simple condition) or with a robot with creative and social behaviors (enhanced condition) in comparison with the same robot that does not display any behaviors (control condition).

\subsection{Participants}

4.2.1 Sample. A total sample of 62 participants took part in this study. Two participants were part of the pilot testing, 20 participants were allocated in each condition. From the total pool of participants, 4 were excluded from the analysis and the final sample was comprised of 56 participants. A detailed description containing the demographics for each group is presented in Table 1. All participants were fluent in oral and written Portuguese language. Participants were randomly assigned to a treatment group by generating a random participant list using the following website: http://random.org.

4.2.2 Ethical selection and participation of children. Participants of this study were children enrolled in summer camps. Data collection included the recruitment of summer camps as a way of accessing children. Summer camps were contacted via email. Upon gathering which camps were interested in being involved in the study, a visit to the summer camp was performed to ensure proper conditions for the study (e.g., having access to a private classroom). During this first visit, the study was presented to the staff consisting of teachers and additional relevant personnel. A presentation session with parents was held to clarify potential doubts. The recruitment process was held jointly with summer camps. A consent form was delivered to the interested camps. The consent form was then delivered to the legal guardians through the camps and only children whose informed consent was returned and signed were included in the study. Written consent of legal guardians and children's verbal assent to engage in the study was required at the time of the intervention session. The main goal of the study was not made explicit in the consent form to ensure internal validity of the results. However, a detailed debriefing is provided to children at the end of the study session and the email contact of the leading researcher was provided in the consent form to in case legal guardians wish to clarify additional questions. 
This study followed the ethical and professional standards of the code of conduct of research in Portugal, which required a commitment to protect the fundamental right to privacy and personal data protection, being subject to the requirements of the General Data Protection Regulation and associated legislation. No monetary or symbolic reward was provided to children who participated in this study. However, children benefited from the study by being exposed to cutting-edge robotic technology.

\subsection{Measures}

This study used two types of measures: measures for the creative person, consisting of tests applied to children as pre- and postmeasures to evaluate their creative skills. Additionally, we included measures for the creative process, which consists in transcribing and coding the all verbal behavioral interactions between the child and the robot during the process of story creation to measure the creative process that children engage in. Both of these measurement types are detailed below.

4.3.1 Creative person. Creative skills of children were evaluated in terms of their verbal creativity and graphic-figural creativity, using validated measures described below:

CREA - Verbal creativity was measured using the CREA test Forms A and C [21], adapted to Portuguese [55]. CREA Form A was used as a baseline measure (pre-test) to analyze children's creativity before the intervention. Form $\mathrm{C}$ was used as a post-test measure to analyze the effects of the intervention on children's creativity. During the CREA application, children are shown an image and instructed to verbally ask as many questions as they can think of about an image. Children have a total of $4 \mathrm{~min}$ to ask questions but they are not made aware of this time limit. The questions of children were voice recorded for posterior analysis and were evaluated following CREA's manual and a single-score for verbal creativity is attributed to each participant.

Test for Creative Thinking-Drawing Production (TCT-DP) - Graphic-figural creativity was measured using the TCT-DP Form A [22], adapted to Portuguese [56]. This test was used as a post-test measure to evaluate the effects of the intervention in children's graphic-figural creativity. During the TCT-DP application, children were presented with an incomplete drawing under the instruction "A painter started this drawing but could not finish it. Your task will be to finish this painting as you wish." Children have a total of $15 \mathrm{~min}$ to finish their drawing but they are not made aware of the time limit. The scoring of the final drawing of children is made according to 14 categories for evaluating figural-graphic creativity, detailed in the test's manual [22]. The final score is divided into the dimensions of Adaptiveness (related with conventional ways of thinking), Innovativeness (related to unconventional ways of thinking, such as breaking of limits, perspectives, and humor), and a total score consisting of a sum of the previous ones [57].

4.3.2 Creative process. Creative processes are defined by being chaotic, messy, and containing the generation of ideas that can be left out or that are not directly visible in the final outcome (see Figure 4). In our scenario, the creative process started when children were introduced to the robot, continued during their story creation, and ended when children finished their stories. During their creative process, a percentage of the generated ideas end up being left out of their final story-line for the sake of converging to the final story plot. If looking only at their final stories, we will not be aware of the creative process they underwent. In the same way, pre-and post-measures do not measure their creative process. However, the discarded ideas are important as they are the expression of children's creative potential. We used the traditional objective scoring system for the cognitive dimensions of creativity comprised of fluency, flexibility, elaboration, and originality [23, 26, 27]. The scoring system is detailed below:

- Fluency - Production of ideas defined by the total number of ideas generated by children that were relevant to the story plot;

- Flexibility - Production of different ideational categories, defined by ideas that fall into different types of categories related to the story plot. These ideas can be related to the characters (role, identity, physical form, wants and needs of the characters), actions (dialogue, movements, and actions of the characters in the story), and scenario (space attributes where the story takes place);

- Elaboration - Persistence on introducing details, defined by the number of details that belong to each of the categories of flexibility;

- Originality - Presence of unusual, surprising, uncommon, but relevant ideas during the creative process that provide additional creative merit to the story. Originality of the story creation process will be rated by the story coders on a scale from 1-4: 1 is meant for very short and non invested stories; 2 for traditional stories that have some action but that are classic stories or replica of existing ones (e.g., a bank robbery is considered a traditional story and the recollection of Star Wars a replica); 3 is meant for stories with a high creative power that are elaborated and that have elements that are surprising but at the same time have a background of a traditional plot; 4 is meant for highly creative and invested stories and is the highest creative score that a story can acquire.

4.3.3 Researcher warmth and competence. To control for the experimenter bias, two questions were asked to children regarding the perceived warmth and competence of R2. The questions were based on the Stereotype Content Model $[58,59]$ and are the following: "How nice was the researcher with you?" (warmth) and "How well did the researcher explained the activity to you?" (competence). Children were invited to answer these questions using a 5-point type-Likert scale designed as a Smily-o-meter [60] and placed their answers in a secret box to ensure additional anonymity and privacy to their answers.

Results showed no differences between conditions regarding the perceived warmth, $F(2,35)=1.03, p=.368, \eta_{\mathrm{p}}^{2}=.06[95 \% \mathrm{CI}: 0.00$, 0.23 ] and competence, $F(2,35)=1.63, p=.850, \eta_{\mathrm{p}}^{2}=.01[95 \% \mathrm{CI}$ : $0.00,0.10]$, of the researcher who applied the intervention. Children rated with high scores researchers' warmth $(M=4.95, S D=.23)$ and competence $(M=4.89, S D=.31)$. This result demonstrates that R1 was perceived similarly across study conditions and the main 
Table 1: Demographic information according to study conditions.

\begin{tabular}{llllll}
\hline & Pilot test & Control condition & Simple condition & Enhanced condition & Total sample \\
\hline Sample (N) & 2 & 20 & 20 & 20 & 62 \\
Excluded (N) & 0 & 1 & 1 & 2 & 4 \\
Age $(\boldsymbol{M} ; \boldsymbol{S D})$ & $8.00 ; .00$ & $7.58 ; 0.69$ & $8.21 ; 0.86$ & $7.83 ; 1.10$ & $7.85 ; 0.96$ \\
Gender (N) & $2 \mathrm{M}$ & $11 \mathrm{M}, 8 \mathrm{~F}$ & $16 \mathrm{M}, 3 \mathrm{~F}$ & $13 \mathrm{M}, 5 \mathrm{~F}$ & $45 \mathrm{M}, 17 \mathrm{~F}$ \\
Siblings $(\boldsymbol{M} ; \boldsymbol{S D})$ & $1.00 ; 1.41$ & $1.37 ; 1.17$ & $0.95 ; 0.85$ & $.83 ; 0.62$ & $1.03 ; 0.91$ \\
\hline
\end{tabular}

results were not caused by a researcher bias.

\subsection{Procedure}

The study was performed in a reserved room ensuring a controlled environment with no interruptions. Two researchers (named R1 and R2, for simplicity) with psychology training were responsible for conducting the study. R1 was responsible for administering the intervention and R2 delivered the pre- and post-tests measures. This requirement was performed to control for experimenter bias.

Before the beginning of the study, R1 coordinated with the summer camp teachers to select one child at the time to perform the session. The child was briefed about the general activities to be performed and gave verbal assent in participating. It was emphasized that there are no right or wrong answers for any question and the child was encouraged to ask questions for additional clarifications. It highlighted that there are no consequences in case the child refused to participate. The study was composed of four moments with an estimated total duration of $30-45 \mathrm{~min}$. The study moments are detailed below:

Moment 1: Pretesting (10-15min): R2 delivered the following questionnaires: demographic information (e.g., age, number of siblings); measure for verbal creativity CREA Form A.

Moment 2: Intervention (no time limit): The main activity took place on the floor of a room to replicate a natural setting where children play with their toys. R1 explained that he/she would play and create a story of their choice using the YOLO robot as a character. R1 explained the instructions while seated on the floor next to the participant to set an informal and relaxed environment, proper for creativity stimulation. When the activity started R1 remained nearby but with minimum interventions. This task had no time-limit and ended when the participant said the story had come to an end.

Moment 3: Posttesting (10-15min): R2 administered the following questionnaires: Graphic-figural creativity will be measured using the Test for Creative Thinking-Drawing Production (TCT-DP; Form A; verbal creativity will be measured using the CREA Form C; R1 warmth and competence levels were evaluated.

Moment 4: Debriefing (post-session time): Debriefing was delivered to the child directly. The way the information was delivered was adapted to the child's level of language and cognition [61]. This meant that researchers were available to answer any questions that children had about the study and the procedures in an understandable way. When children did not ask direct questions at the end of the study, the research voluntarily debriefed children by explaining that the goal of the study was to investigate how they play with toys and how these can affect their creativity.

\subsection{Researcher role}

R1, who was responsible for administering the intervention, had a peripheral role during the activity of storytelling between children and the robot. To minimize interventions in the creative process of children, R1 interventions occurred only to unblock the creative process which occurred when children did not have more ideas for the story during a certain amount of time. In this case, the researcher asks them motivating questions, such as, "what happens next?" or "what is your character doing now?". If children are not providing ideas in the initial part of the storytelling, the researcher introduces dramatic elements, such as "can you tell me where your story happens?" or "are there more characters in your story?". The researcher refrained from providing ideas to the story. The researcher also helped to conclude the story when children did not provide more ideas towards the final stage, by asking questions such as "can you tell me how your story ends?" or "how would you like to finish your story?”.

\section{RESPONSIBLE RESEARCH}

This work adhered to quality standards on research, such as preregistration, open-access, and practices to avoid researcher bias.

\subsection{Pre-registration}

This study was preregistered in Alves-Oliveira et al. [62]. Therefore, research questions, hypotheses, methods, materials, and planned statistical analyses have been preregistered. By doing so, we have defined the research questions and analysis plan before observing the research outcomes, providing credibility to the research findings and contributing to best practices amongst the research community $[63,64]$.

\subsection{Open-access practices}

Materials for this study were provided open-access with this publication in Alves-Oliveira et al. [65]. The release of the collected data enables the replication of the results and contributes to research transparency. Additionally, we provide open access to the measures used accompanied by the verbal instructions of the researcher. This enables the replication, reproduction, or re-creation of the procedure of the study. 


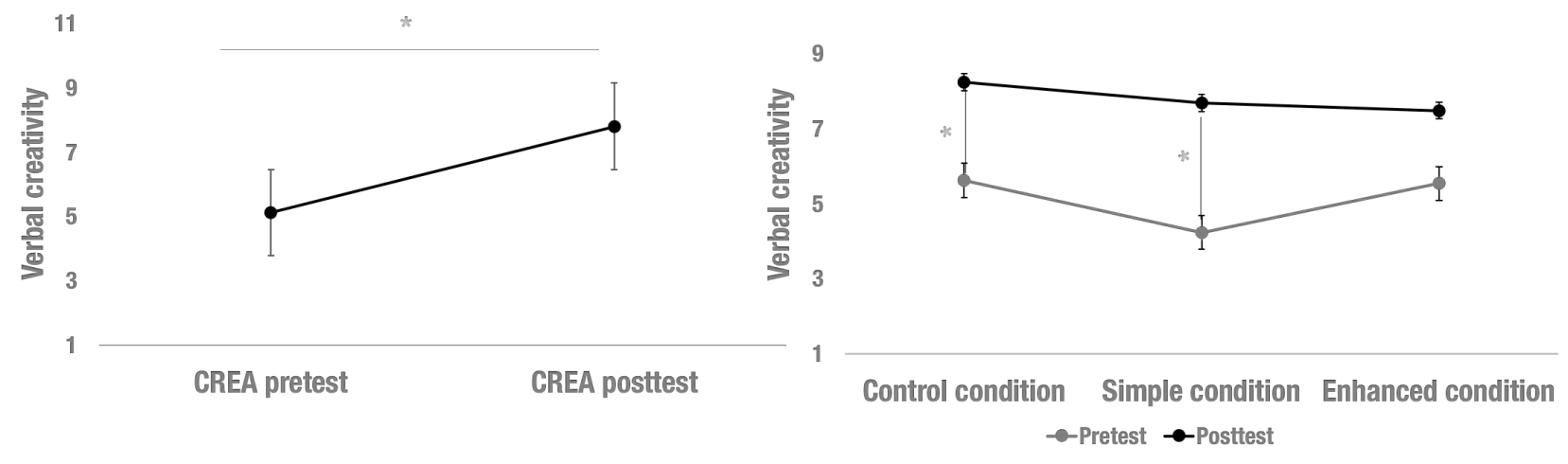

Figure 5: Left: Main effect of verbal creativity measured with CREA from the pre- to the post-tests, $p<.05$. Right: Significant increase from pre- to post-tests scores of verbal creativity for the Control and Simple conditions, $p<.05$.

\subsection{Avoiding experimenter bias}

Researcher bias is defined by the results being affected because the same experimenter who facilitates activity also administers the measures [66]. To avoid experimenter bias, researchers and participants should be blinded to the study conditions. When this double-blind testing is not possible, some techniques can help to reduce the experimenter bias, which we have applied in our study [67]. One technique is to have two researchers involved in the study, $\mathrm{R} 1$ and R2, each of them responsible for administering the intervention (R1) and delivering measures (R2). As R1 was not blinded to the conditions as the robot behavior make it explicit about what was being measured, we applied an additional measure to reduce bias. Therefore, participants were asked to evaluate R1's warmth and competence, two fundamental dimensions of social perception that can contribute to the bias $[58,59]$. To ensure additional anonymity and privacy of children, a secret box where they placed their answers was provided. This was applied by $\mathrm{R} 2$ at a post-test stage and signals the closure of the activity. Details about the result for this controlled factor can be seen in section 6 .

\section{RESULTS}

We present the analysis of the results for the creative person (H1) and the creative process $(\mathrm{H} 2)$ in light of our hypothesis.

H1: The impact of the intervention on verbal and graphicfigural creativity will be higher in the experimental conditions compared to the control group.

A 2 (Phase: pre/post assessment) X 3 (Group) analysis of variance (ANOVA) was used to analyze the results of verbal creativity with CREA. The results showed a statistical significant main effect of Phase, $F(1,50)=15.20, p<.001, \eta_{\mathrm{p}}^{2}=.23$ [95\% CI: 0.06, 0.44], indicating an increase in the overall creativity scores from pre- to post-testing ( $M=5.12, S D=0.44$ vs. $M=7.79, S D=0.65$ ) (see Figure 5). There was no significant main effect of Group, $F(2,50)=0.42$, $p=.657, \eta_{\mathrm{p}}^{2}=.02$ [95\% CI: $\left.0.00,0.11\right]$, nor an interaction between Phase X Group, $F(2,50)=0.40, p=.671, \eta_{\mathrm{p}}^{2}=.02$ [95\% CI: 0.00, 0.11]. Thus, for all group conditions, the results of CREA were similar at baseline, $F(2,50)=1.08, p=.347, \eta_{\mathrm{p}}^{2}=.04$ [95\% CI: 0.00, 0.17], and after the intervention, $F(2,50)=0.12, p=.888, \eta_{\mathrm{p}}^{2}=.005[95 \% \mathrm{CI}$ : $0.00,0.06]$.

A one-way between subjects ANOVA was used to compare the effect of Group (3 conditions) on graphic-figural creativity with TCT-DP. We recall that graphic-figural creativity was measured according to the two dimensions of TCT-DP: Adaptiveness and Innovativeness. There were no statistically significant differences between groups for both adaptiveness, $F(2,53)=.11, p=.897$, and innovativeness, $F(2,53)=.07, p=.930$. TCT-DP total score was also similar between conditions, $F(2,53)=.09, p=.918$. Despite no differences between conditions, normative values for this test showed that children were between the 50 and the 70 percentile, denoting a medium-high of graphic-figural creativity levels after intervention [57].

Taken together, the results showed that verbal creativity levels increased for all study conditions as an effect of the intervention. Additionally, verbal creativity levels statistically increased more from pre- to post-testing in the Simple condition compared to Control. Overall, the results partially support the hypothesis.

H2: Children's creative process of storytelling is more creative in the experimental conditions compared to control.

We used a one-way ANOVA to analyze the creative process of storytelling according to its fluency, flexibility, elaboration, and originality in terms of Conditions (3 groups).

The ANOVA for the fluency scores revealed no significant differences in the number of ideas generated between the Groups, $F(2$, $52)=.06, p=.943, \eta_{\mathrm{p}}^{2}=.001$ [95\% CI: 0.00, 0.08].

Flexibility was evaluated in terms of the different ideational categories of drama, which consist of characters, action, and scenario. Planned contrasts showed a marginally significant result for characters between the Control and Enhanced conditions, $t=1.94, p=.05$, $d=0.66$ [95\% CI: $-0.03,1.30]$, with more ideas being generated in the Enhanced condition $(M=12.50, S D=2.46)$ than in the Control condition $(M=7.42, S D=1.17)$ (see Figure 6, left). No additional result was found for action, $F(2,52)=.09, p=.996, \eta_{\mathrm{p}}^{2}=.002[95 \%$ 


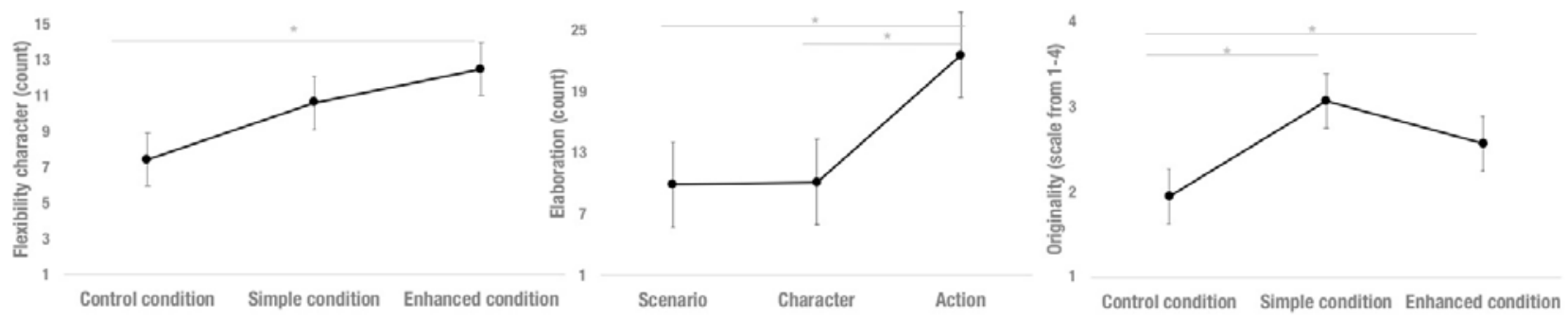

Figure 6: Left: Number of ideas generated by children about their characters during story creation. The graph shows a significant difference between the Control and the Enhanced conditions, $p<.05$. Middle: Elaboration of ideas related to the story's actions was significantly higher than ideas generated towards the story character or scenario, $p<.05$. Right graph: Ratings of originality for the creative process of story creation. The graph shows the creative process of storytelling was more original in both the Simple and the Enhanced conditions in comparison to Control, $p<.05$.

CI: $0.00,0.08]$, and scenario, $F(2,52)=.07, p=.929, \eta_{\mathrm{p}}^{2}=.001[95 \%$ CI: $0.00,0.08]$.

There was a statistically significant main effect of the Conditions (3 Groups) on elaboration, $F(1,54)=58.99, p<.001, \eta_{\mathrm{p}}^{2}=.52[95 \%$ CI: $0.32,0.69$ ], with more ideas being generated towards the story action $(M=22.60, S E=2.08)$ in comparison with the story characters $(M=10.13, S E=1.09)$ and scenario $(M=9.87, S E=0.93)$ (see Figure 6 middle graph).

There was a significant main effect of group on originality, $F(2$, $52)=7.35, p=.002, \eta_{\mathrm{p}}^{2}=.22$, [95\% CI: 0.04, 0.41]. (see Figure 6, right). Planned contrasts showed that this difference occurred between the two experimental conditions and the control, $t(52)=3.44, p=$ $.001, d=0.94$, [95\% CI: 0.38, 1.56]. When looking at the means, the Simple $(M=3.06, S D=.94, t(52)=3.83, p<.001, d=1.29$, [95\% CI: $0.54,1.96])$ and the Enhanced conditions $(M=2.56, S D=.78, t(52)$ $=2.10, p=.041, d=0.71$ [95\% CI: 0.02, 1.35]) were superior than $\operatorname{control}(M=1.95, S D=.91)$.

Effect sizes for the significant effects are large, demonstrating the strength of the results. Overall, the results partially supported this hypothesis.

\section{DISCUSSION AND CONCLUSION}

In this work, we presented an experimental study investigating the effects of using a social robot for creativity interventions with children. We have conducted a study in which a social robot named YOLO was used within the context of unstructured play and storytelling, both familiar contexts of interaction for children. We have used the YOLO robot as the behaviors of this robot were designed grounded on validated creativity techniques. We investigated the effectiveness of YOLO in stimulating children's creativity not only at pre- and post-test levels but also during their creative process. An additional novelty concerns the way that children can interact with this robot during the intervention. Namely, this robot is portable, light, and thus can serve the purposes of being a character in children's stories with flexibility.

Our results showed the potential of using the YOLO robot for creativity stimulation in children. When using YOLO loaded with creativity behaviors during play, children engaged in a more original and creative process. Although this result is not evident in post-testing measures, the creative process experience they engaged in with the robot leads to more innovative, rare, and novel ideas, unlocking creative processes related to creative thought. This result has implications for the understanding of how humans create while using robots as their tools.

This study was designed taking into consideration research quality standards, such as pre-registration and open access. Therefore, in this paper, we presented partial evidence that resulted from the design study that was pre-registered. Future work includes studying creativity in a group context since literature shows that group effects play an important role in creative expression.

In sum, this work provides important insights for using social robots to stimulate the creative process of children. As creativity is considered a transferable skill, it is expected that children will be able to be creative in other endeavors of their life when trained and stimulated for creativity. Overall, this work aimed at contributing to the field of human-robot interaction (HRI) by providing evidence that robots can be used to support innate human qualities, such as the ability to be creative, which is a beneficial capacity to have during childhood but also during adulthood.

\subsection{Highlights}

- We have tested a fully autonomous robot that acted as a tool for creative stimulation. This evaluation was conducted into-the-wild, in summer camps, with children.

- We have evaluated the creative process of children when creating a story together with a robot. We relied on a validated scoring system to analyze the creative process.

- We released in open-access the materials, datasets, instructions, and questionnaires for this study. Additionally, this study was pre-registered in Open Science Framework.

\section{ACKNOWLEDGMENTS}

We show our gratitude to Professor Sara Ibérico Nogueira and to Beatriz Maia for their involvement in this study. This work was supported by national funds through FCT, Fundação para a Ciência e a Tecnologia, under project UIDB/50021/2020 and P. Alves-Oliveira acknowledges an FCT Grant, FRH/BD/110223/2015. 


\section{REFERENCES}

[1] R. Ritchhart and K. Robinson, "Out of our minds: Learning to be creative," 2001

[2] S. W. Russ, A. L. Robins, and B. A. Christiano, "Pretend play: Longitudinal prediction of creativity and affect in fantasy in children," Creativity Research fournal, vol. 12 , no. 2, pp. 129-139, 1999.

[3] B. W. Roberts and D. Mroczek, "Personality trait change in adulthood," Current directions in psychological science, vol. 17, no. 1, pp. 31-35, 2008.

[4] A. Gopnik, T. L. Griffiths, and C. G. Lucas, "When younger learners can be better (or at least more open-minded) than older ones," Current Directions in Psychological Science, vol. 24, no. 2, pp. 87-92, 2015.

[5] K. Robinson, Out of our minds: Learning to be creative. Mankato, MN, USA: Capstone, 2011.

[6] P. Collard and J. Looney, "Nurturing creativity in education," European fournal of Education, vol. 49, no. 3, pp. 348-364, 2014.

[7] J. Baer, "Content matters: Why nurturing creativity is so different in different domains," in Creative Contradictions in Education, R. A. Beghetto and B. Sriraman, Eds. Switzerland: Springer, Cham, 2017, pp. 129-140.

[8] J. Kaufman, "Creativity as a stepping stone toward a brighter future," fournal of Intelligence, vol. 6, no. 2, pp. 1-7, 2018.

[9] D. Chadha, "A curriculum model for transferable skills development," engineering education, vol. 1, no. 1, pp. 19-24, 2006.

[10] T. Lewis, "Creativity in technology education: Providing children with glimpses of their inventive potential," International fournal of Technology and Design Education, vol. 19 , no. 3, pp. 255-268, 2009.

[11] J. S. Dacey, "Peak periods of creative growth across the lifespan," The fournal of Creative Behavior, vol. 23, no. 4, pp. 224-247, 1989.

[12] N. Kogan, "Creativity and cognitive style: A life-span perspective," in Life-Span Developmental Psychology: Personality and Socialization, P. B. Baltes and K. W. Schaie, Eds. Cambridge, MA, USA: Academic Press, 1973, pp. 145-178.

[13] R. K. Sawyer, M. Csikszentmihalyi, V. John-Steiner, S. Moran, D. H. Feldman, H. Gardner, R. J. Sternberg, J. Nakamura et al., Creativity and development. New York, NY, USA: Oxford University Press, 2003.

[14] B. Spodek and O. N. Saracho, Handbook of research on the education of young children. Routledge, 2014.

[15] K. H. Kim, "The creativity crisis: The decrease in creative thinking scores on the torrance tests of creative thinking," Creativity Research fournal, vol. 23, no. 4, pp. 285-295, 2011.

[16] D. B. Haun and M. Tomasello, "Conformity to peer pressure in preschool children," Child development, vol. 82, no. 6, pp. 1759-1767, 2011

[17] M. A. Runco, S. Acar, and N. Cayirdag, "A closer look at the creativity gap and why students are less creative at school than outside of school," Thinking Skills and Creativity, vol. 24, pp. 242-249, 2017.

[18] G. Scott, L. E. Leritz, and M. D. Mumford, "The effectiveness of creativity training: A quantitative review," Creativity research journal, vol. 16, no. 4, pp. 361-388, 2004.

[19] S. Chan and M. Yuen, "Personal and environmental factors affecting teachersâĂŹ creativity-fostering practices in hong kong," Thinking Skills and Creativity, vol. 12, pp. 69-77, 2014.

[20] T. Belpaeme, J. Kennedy, A. Ramachandran, B. Scassellati, and F. Tanaka, "Social robots for education: A review," Science robotics, vol. 3, no. 21, p. eaat5954, 2018

[21] F. J. Corbalán Berná, F. Martínez Zaragoza, D. S. Donolo, C. Alonso Monreal, M. Tejerina Arreal, and R. M. Limiñana Gras, "Crea. inteligencia creativa. una medida cognitiva de la creatividad," 2003.

[22] H. G. Jellen and K. K. Urban, "The tct-dp (test for creative thinking-drawing production): An instrument that can be applied to most age and ability groups." Creative Child \& Adult Quarterly, 1986.

[23] J. P. Guilford, "The nature of human intelligence." 1967

[24] R. M. Netting, Cultural ecology, 1986, no. 304.2 N47.

[25] J. Forlizzi, "The product ecology: Understanding social product use and supporting design culture," International fournal of design, vol. 2, no. 1, 2008

[26] E. P. Torrance, Torrance tests of creative thinking: Norms-technical manual: Verbal tests, forms $a$ and $b$ : Figural tests, forms $a$ and $b$. Personal Press, Incorporated, 1966.

[27] R. J. Sternberg, "Creativity or creativities?" International fournal of HumanComputer Studies, vol. 63, no. 4-5, pp. 370-382, 2005.

[28] L. W. Anderson, D. R. Krathwohl, P. W. Airasian, K. A. Cruikshank, R. E. Mayer P. R. Pintrich, J. Raths, and M. C. Wittrock, "A taxonomy for learning, teaching, and assessing: A revision of bloomâĂŹs taxonomy of educational objectives, abridged edition," White Plains, NY: Longman, 2001.

[29] C. W. Taylor, "Various approaches to and definitions of creativity," The nature of creativity, pp. 99-121, 1988.

[30] R. E. Mayer, "22 fifty years of creativity research," Handbook of creativity, vol. 449, 1999.

[31] J. A. Plucker, R. A. Beghetto, and G. T. Dow, "Why isn't creativity more important to educational psychologists? potentials, pitfalls, and future directions in creativity research," Educational psychologist, vol. 39, no. 2, pp. 83-96, 2004.
[32] T. M. Amabile, Creativity in context: Update to the social psychology of creativity. Hachette UK, 1996.

[33] K. Sawyer, Group genius: The creative power of collaboration. Basic Books, 2017.

[34] R. K. Sawyer, "Individual and group creativity," The Cambridge handbook of creativity, pp. 366-380, 2010.

[35] P. B. Paulus and B. A. Nijstad, Group creativity: Innovation through collaboration. Oxford University Press, 2003.

[36] J. Mueller and M. A. Cronin, "How relational processes support team creativity," in Creativity in groups. Emerald Group Publishing Limited, 2009, pp. 291-310.

[37] M. A. Cronin and J. Loewenstein, The Craft of Creativity. Stanford University Press, 2018.

[38] J. A. Plucker and M. C. Makel, "Assessment of creativity," The Cambridge handbook of creativity, pp. 48-73, 2010.

[39] J. Baer and S. S. McKool, "Assessing creativity using the consensual assessment technique," in Handbook of research on assessment technologies, methods, and applications in higher education. IGI Global, 2009, pp. 65-77.

[40] D. H. Cropley and J. C. Kaufman, "Measuring functional creativity: Non-expert raters and the creative solution diagnosis scale," The fournal of Creative Behavior, vol. 46, no. 2, pp. 119-137, 2012.

[41] P. H. Kahn Jr, T. Kanda, H. Ishiguro, B. T. Gill, S. Shen, J. H. Ruckert, and H. E. Gary, "Human creativity can be facilitated through interacting with a social robot," in The Eleventh ACM/IEEE International Conference on Human Robot Interaction. IEEE Press, 2016, pp. 173-180.

[42] S. Ali, T. Moroso, and C. Breazeal, "Can children learn creativity from a social robot?" in Proceedings of the 2019 on Creativity and Cognition. ACM, 2019, pp. $359-368$.

[43] J. E. Pretz and D. Nelson, "Creativity is influenced by domain, creative self-efficacy, mindset, self-efficacy, and self-esteem," in The creative self. Elsevier, 2017, pp. $155-170$.

[44] M. Karwowski, "Creative mindsets: Measurement, correlates, consequences." Psychology of Aesthetics, Creativity, and the Arts, vol. 8, no. 1, p. 62, 2014.

[45] R. W. Hass, J. Katz-Buonincontro, and R. Reiter-Palmon, "Disentangling creative mindsets from creative self-efficacy and creative identity: Do people hold fixed and growth theories of creativity?" Psychology of Aesthetics, Creativity, and the Arts, vol. 10, no. 4, p. 436, 2016.

[46] H. W. Park, R. Rosenberg-Kima, M. Rosenberg, G. Gordon, and C. Breazeal, "Growing growth mindset with a social robot peer," in 2017 12th ACM/IEEE International Conference on Human-Robot Interaction (HRI. IEEE, 2017, pp. 137-145.

[47] L. P. Hagtvedt, K. Dossinger, S. H. Harrison, and L. Huang, "Curiosity made the cat more creative: Specific curiosity as a driver of creativity," Organizational Behavior and Human Decision Processes, vol. 150, pp. 1-13, 2019

[48] G. Gordon, C. Breazeal, and S. Engel, "Can children catch curiosity from a social robot?" in 2015 10th ACM/IEEE International Conference on Human-Robot Interaction (HRI). IEEE, 2015, pp. 91-98.

[49] J. Ceha, N. Chhibber, J. Goh, C. McDonald, P.-Y. Oudeyer, D. Kulić, and E. Law, "Expression of curiosity in social robots: Design, perception, and effects on behaviour," in Proceedings of the 2019 CHI Conference on Human Factors in Computing Systems. ACM, 2019, p. 406.

[50] P. Alves-Oliveira, P. Arriaga, A. Paiva, and G. Hoffman, "Guide to build yolo, a creativity-stimulating robot for children," HardwareX, vol. 6, p. e00074, 2019

[51] W. Ju, "The design of implicit interactions," Synthesis Lectures on Human-Centered Informatics, vol. 8, no. 2, pp. 1-93, 2015.

[52] A. B. VanGundy, Techniques of structured problem solving. Springer, 1988.

[53] T. Rickards, Problem-solving through creative analysis. Wiley, 1975.

[54] P. Alves-Oliveira, S. Gomes, A. Chandak, P. Arriaga, G. Hoffman, and A. Paiva, "Software architecture for yolo, a creativity-stimulating robot," arXiv preprint arXiv:1909.10823, 2019.

[55] J. Duarte, S. Imaginário, and S. Jesus, "Criatividade em estudantes universitários. validação preliminar do crea em portugal. instituto de psicologia cognitiva, desenvolvimento vocacional e social," Psycaware e-journal, 2010.

[56] L. Almeida and S. I. Nogueira, "Estudo preliminar do teste test for creative thinking-drawing production (tct-dp)," Psychologica, no. 52-I, pp. 193-210, 2010.

[57] S. I. Nogueira, L. S. Almeida, and T. S. Lima, "Two tracks of thought: A structural model of the test for creative thinking-drawing production (tct-dp)," Creativity Research fournal, vol. 29, no. 2, pp. 206-211, 2017.

[58] A. J. Cuddy, S. T. Fiske, and P. Glick, "Warmth and competence as universal dimensions of social perception: The stereotype content model and the bias map," Advances in experimental social psychology, vol. 40, pp. 61-149, 2008.

[59] S. Fiske, A. Cuddy, P. Glick, and J. Xu, "A model of stereotype content as often mixed: Separate dimensions of competence and warmth respectively follow from status and competition," Fournal of Personality and Social Psychology, vol. 82, no. 6, pp. 878-902, 2002.

[60] J. C. Read, "Validating the fun toolkit: an instrument for measuring childrenâĂŹs opinions of technology," Cognition, Technology \& Work, vol. 10, no. 2, pp. 119-128, 2008.

[61] J. C. Read, M. Horton, G. Sim, P. Gregory, D. Fitton, and B. Cassidy, "Check: a tool to inform and encourage ethical practice in participatory design with children," 
in CHI'13 Extended Abstracts on Human Factors in Computing Systems. ACM 2013, pp. 187-192.

[62] P. Alves-Oliveira, P. Arriaga, M. A. Cronin, A. Paiva, and G. Hoffman, "Creativity encounters," Retrieved from osf.io/ hyxfu, 2019.

[63] B. A. Nosek, C. R. Ebersole, A. C. DeHaven, and D. T. Mellor, "The preregistration revolution," Proceedings of the National Academy of Sciences, vol. 115, no. 11, pp 2600-2606, 2018.

[64] B. Irfan, J. Kennedy, S. Lemaignan, F. Papadopoulos, E. Senft, and T. Belpaeme, "Social psychology and human-robot interaction: An uneasy marriage," in Companion of the 2018 ACM/IEEE International Conference on Human-Robot Interaction.
ACM, 2018, pp. 13-20.

[65] P. Alves-Oliveira, P. Arriaga, M. A. Cronin, and A. Paiva, "Creativity encounters between children and robots," Retrieved from https://doi.org/10.17605/OSF.IO/ VKSR5, 2020.

[66] S. W. Russ, "Demonstrating effects with children: When do we know we know?" 2014.

[67] R. E. Larzelere, B. R. Kuhn, and B. Johnson, "The intervention selection bias: an underrecognized confound in intervention research." Psychological bulletin, vol. 130, no. 2, p. $289,2004$. 